\title{
Prevalência de anticorpos contra o vírus da arterite equina nas mesorregiões Noroeste, Centro Ocidental e Norte Central do Paraná
}

\author{
Prevalence of antibodies against equine viral arteritis virus in Northwest, \\ Western Central and North Central Regions of the State of Paraná, Brazil \\ Luciana Sartori ${ }^{1 *}$, Maria do Carmo Custódio de Souza Hunold Lara²,
Eliana Monteforte Cassaro Villalobos ${ }^{2}$, Júlio Augusto Naylor Lisbôa ${ }^{1}$
}

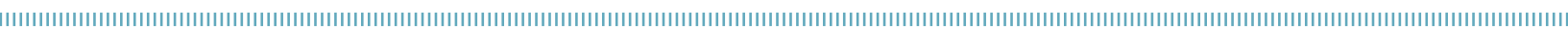

RESUMO: O objetivo deste estudo foi investigar a prevalência de anticorpos contra o vírus da arterite viral equina (EVAV) em equinos sadios criados nas mesorregióes Noroeste, Centro Ocidental e Norte Central do estado do Paraná. Após o cálculo do tamanho amostral, foram analisadas, utilizando a técnica de soroneutralização, amostras de soro sanguíneo de 653 equinos. Nenhum animal sororreagente foi encontrado nas mesorregióes Noroeste $(0 / 236)$ e Centro Ocidental (0/99). Na mesorregião Norte Central a prevalência foi de $0,62 \%$ (2/318), totalizando $0,30 \%$. Pode-se concluir que a arterite viral equina (AVE) ainda não representa um problema de importância epidemiológica nos equinos criados nas mesorregióes paranaenses estudadas.

PALAVRAS-CHAVE: equinos; arterite viral equina; epidemiologia; doenças víricas.
ABSTRACT: The prevalence of antibodies against equine viral arteritis virus (EVAV) in healthy horses raised in Northwest, Western Central and North Central regions of the State of Paraná, Brazil was investigated. According to calculated sample size, serum samples of 653 horses were analyzed through standard virus neutralization test. No horse had antibodies to EVAV in Northwest (0/236) and in Western Central (0/99) regions. In North Central region frequency was $0.62 \%$ (2/318), with an overall prevalence of $0.30 \%$. It can be concluded that EVA does not represent a problem of epidemiological importance in the studied regions of Paraná.

KEYWORDS: equine; equine viral arteritis; epidemiology; viral diseases. 
A arterite viral equina (AVE) é uma doença infectocontagiosa dos equídeos causada por um vírus RNA envelopado, do gênero Arterivirus, e pertencente à família Arteriviridae (Lima; Osorio, 2012) que foi isolado pela primeira vez em 1984, durante um surto de abortamento ocorrido em Ohio, Estados Unidos da América (EUA) (Timoney; Mccollum, 1993). A transmissão ocorre principalmente pela via respiratória, por contato com as secreçóes do animal doente, e pela via genital ou venérea, por meio de contato com sêmen fresco ou congelado do garanhão infectado (HOLYOAK et al., 2008).

A doença respiratória, caracterizada por sinais inespecíficos de envolvimento das vias aéreas craniais, e os abortamentos, que podem ocorrer na forma de surtos e em qualquer fase da gestação, são as duas principais formas de manifestaçấo da doença (HOLYOAK et al., 2008). O garanhão pode tornar-se portador assintomático e eliminar o vírus no sêmen por período de tempo indeterminado (Lima; Osorio, 2012). Os prejuízos econômicos devem-se a perda da prenhez, natimortalidade ou mortalidade neonatal, custos com o tratamento e diminuiçáo do valor comercial do sêmen.

Surtos de AVE foram confirmados em todos os continentes e os relatos são mais frequentes nos EUA e em países europeus (Bell et al., 2006). O primeiro isolamento do vírus da arterite viral equina (EVAV) na América do Sul ocorreu na Argentina (Echeverria et al., 2003).

No Brasil, apesar de nunca ter sido isolado, os levantamentos soroepidemiológicos indicam que o vírus circula pelo país. Estudos sobre a frequência de anticorpos contra o EVAV foram realizados nos estados de Sáo Paulo (Fernandes; Souza,1999; Souza, 1999; Lara et al., 2002; 2003b; CunHa et al., 2009; Braga et al., 2012), do Rio Grande do Sul (Diel et al., 2006), de Minas Gerais (Bello et al., 2007), de Rondônia (Aguiar et al., 2008) e do Pará (Heinemann et al., 2002). No estado do Paraná foram realizados dois levantamentos e ambos se limitaram a equinos mantidos na Região Metropolitana de Curitiba (LARA et al., 2003a; 2006). Para aumentar a abrangência geográfica da informação no Estado, o presente estudo teve o objetivo de investigar a prevalência de anticorpos contra o EVAV em equinos criados em três mesorregiốes geográficas paranaenses: Noroeste, Norte Central e Centro Ocidental.

$\mathrm{O}$ estudo abrangeu 75 municípios em 3 mesorregiôes paranaenses: Noroeste (19 municípios), Centro Ocidental
(23 municípios) e Norte Central (33 municípios) (Fig. 1). Essas mesorregióes contam com um rebanho de equinos com 111.219 cabeças no total, o que representa $29,9 \%$ do rebanho do estado do Paraná (Brasil, 2010). As amostras utilizadas foram selecionadas de um conjunto de soros sanguíneos de equinos aparentemente sadios (2.742 unidades no total) criados nessas mesorregióes. Os soros foram obtidos no período de fevereiro de 2010 a agosto de 2012 com a finalidade de realizaçáo do exame de imunodifusão em gel de ágar para o diagnóstico de anemia infecciosa equina (AIE). Posteriormente ao exame, foram mantidos congelados a $-20^{\circ} \mathrm{C}$.

Para o cálculo do número de amostras a serem analisadas, admitiram-se valor de prevalência (p) de 5,71\%, (BRAGA et al., 2012), erro (d) de $2 \%$, efeito de delineamento de amostragem (DEFF) de 1,5 e nível de significância de 5\%. A seguinte equaçâo foi utilizada empregando-se o programa Epi Info, versão 6.04: $\mathrm{n}=\left[\operatorname{DEFF}^{*} \mathrm{~Np}(1-\mathrm{p})\right] /\left[\left(\mathrm{d}^{2} / \mathrm{Z}^{2}{ }_{1-\alpha / 2}{ }^{*}(\mathrm{~N}-1)+\mathrm{p}^{*}(1-\mathrm{p})\right]\right.$, sendo $\mathrm{No}$ tamanho da população. Foram analisadas amostras de 653 equinos no total e definiu-se que o número de amostras de cada mesorregiáo seria ponderado de acordo com a proporção da populaçấo existente nesses locais (Tabela 1). A seleção das amostras foi estabelecida por sorteio, evitando-se as repetiçóes por município e por rebanhos, sempre que viável. Esse critério foi adotado com o objetivo de alcançar a maior abrangência geográfica possível. Repetiçóes por municípios foram inevitáveis em 204 amostras e repetições no mesmo rebanho ocorreram em 138 amostras.

A técnica de soroneutralizaçâo em placas de 96 cavidades, padronizada por SENNE et al. (1985) e recomendada pela Organização Mundial de Saúde Animal (OIE), foi empregada para a deteç̧ão da presença dos anticorpos séricos contra o EVAV. O soro foi incubado com $100 \mathrm{DICT}_{50} / 25 \mu \mathrm{L}$ do EVAV (amostra Bucyrus), durante 1 hora, a $37^{\circ} \mathrm{C}$. Após esse período, $100 \mu \mathrm{L}$ da suspensáo de células da linhagem RK-13 (rim de coelho), contendo 300.000 células $/ \mathrm{mL}$, foram adicionados a cada cavidade e as placas foram mantidas incubadas em estufa a $37^{\circ} \mathrm{C}$ com $5 \%$ de $\mathrm{CO}_{2}$ durante 72 horas. A leitura foi realizada para verificaçáo da presença ou não dos efeitos citopáticos nos cultivos celulares. Foram considerados reagentes os animais que possuíam anticorpos neutralizantes no soro diluído 1:4.

Tabela 1. Mesorregiões geográficas paranaenses, populações de equinos correspondentes, número de amostras estudadas e frequência de equinos sororreagentes ao vírus da arterite viral equina.

\begin{tabular}{|c|c|c|c|c|c|}
\hline $\begin{array}{l}\text { Mesorregião } \\
\text { geográfica }\end{array}$ & $\begin{array}{l}\text { População } \\
\text { de equinos* }\end{array}$ & $\begin{array}{c}\text { Proporção } \\
\text { da população }\end{array}$ & $\begin{array}{c}\text { Amostras } \\
\text { examinadas }\end{array}$ & Reagentes & IC95\% \\
\hline Noroeste & 52.801 & $47 \%$ & 236 & $\mathrm{O}(0 \%)$ & $0-1,55$ \\
\hline Centro Ocidental & 12.941 & $12 \%$ & 99 & $\mathrm{O}(0 \%)$ & $0-3,65$ \\
\hline Norte Central & 45.476 & $41 \%$ & 318 & $2(0,62 \%)$ & $0,07-2,25$ \\
\hline Total & 111.218 & $100 \%$ & 653 & $2(0,30 \%)$ & $0,04-1,10$ \\
\hline
\end{tabular}

*Fonte: Censo Agropecuário de 2009 (BRASIL, 2010). IC95\%: intervalo de confiança de 95\%. 
Nenhum animal positivo foi detectado tanto na mesorregiáo Noroeste (0/236) quanto na mesorregiáo Centro Ocidental (0/99). Animais reagentes (2/318) foram encontrados somente na mesorregiāo Norte Central. A frequência encontrada foi de $0,62 \%$ nessa mesorregião, sendo $0,30 \%$ a frequência total no estudo (Tabela 1).

A população estudada foi composta por 313 fêmeas $(47,9 \%)$ e 340 machos $(52,1 \%)$. Na sua maioria, eram equinos adultos: $80 \%$ estavam entre o $3^{\circ}$ e o $10^{\circ}$ ano de idade e somente $5 \%$ tinham até 24 meses de vida. A metade dos animais era da raça Quarto de Milha (52,1\% das amostras) e os mestiços representaram o segundo maior contingente $(33,8 \%$ das amostras). Era, portanto, caracterizada principalmente por equinos que participavam de eventos esportivos, feiras agropecuárias e cavalgadas, situaçóes em que se aglomeram animais de diferentes procedências. $\mathrm{O}$ deslocamento desde a propriedade de origem tornava necessária a realizaçáo do exame de AIE, requisito obrigatório para a emissão da Guia de Trânsito Animal (GTA).

Os resultados obtidos são compatíveis com outros estudos realizados em diferentes estados brasileiros, nos quais o número de animais reagentes foi muito reduzido ou ausente. Heinemann et al. (2002), trabalhando no Pará, Aguiar et al. (2008), em Rondônia, e CunHa et al. (2009), no sul do estado de São Paulo, não observaram equídeos portadores de anticorpos contra o EVAV. Prevalências de anticorpos reduzidas foram obtidas por Souza et al. (1999) no Vale do Paraíba, São Paulo (1,04\%), por LarA et al. (2003b) na regiāo de Araçatuba, Sáo Paulo (0,3\%), por Diel et al. (2006) no Rio Grande do Sul $(2,2 \%)$ e por Bello et al. (2007) em Minas Gerais (0,85\%). Nos dois levantamentos realizados anteriormente no estado do Paraná também foram observadas prevalências nula (LARA et al., 2006) ou reduzida (2,9\%) (LARA et al., 2003a).

Os três levantamentos brasileiros que demonstraram maior número de equinos reagentes foram realizados no estado de Sáo Paulo e apresentaram resultados que diferem dos obtidos no presente trabalho. Fernandes; Souza (1999), Lara et al. (2002) e Braga et al. (2012) observaram, respectivamente, que 19,3, 18,2 e 5,7\% dos equinos sadios testados eram sororreagentes. Em animais com história recente de abortamento ou de doença respiratória, as frequências de sororreagentes foram 10,3 e 23,5\%, respectivamente (Fernandes; Souza, 1999).

Na maior parte dos estudos com número reduzido ou nulo de portadores de anticorpos contra o EVAV, os animais testados eram utilizados para trabalho nas propriedades e o risco de exposição ao vírus era reduzido porque, geralmente, não eram transportados para fora das propriedades e não entravam em contato com outros animais de origens diversas (Souza et al., 1999; Heinemann et al., 2002; Lara et al., 2003b; Aguiar et al., 2008; CUNHA et al., 2009). Esses autores consideraram que essa era justamente a razão para os resultados observados. Ao contrário, as maiores frequências de sororreagentes foram observadas em equinos criados para reproduçấo ou esporte
(Fernandes; Souza, 1999; Lara et al., 2002; Braga et al., 2012), os quais estão frequentemente sujeitos a trânsito e a contato com outros animais de origens variadas, aumentando a chance de contágio com o vírus.

Pelas características já mencionadas, os animais testados no presente trabalho também estariam sujeitos a risco elevado de contágio com o vírus. O mesmo pode ser dito sobre os equinos estudados por Diel et al. (2006), visto que eram animais criados com a finalidade de esporte, reproduçáo e exposição, cujos soros sanguíneos foram obtidos igualmente para o exame de AIE. Apesar da maior probabilidade de contágio, o número de animais reagentes também foi reduzido.

A existência de discrepâncias regionais na prevalência de anticorpos contra o EVAV está bem documentada nos diferentes estudos realizados em São Paulo, estado que possui a maior circulação do vírus, aparentemente. Regiôes de prevalência elevada (Fernandes; SouZA, 1999; Lara et al., 2002; BRAGA et al., 2012) contrastam com outras de frequência reduzida (Souza et al., 1999; LaRA et al., 2003b; CunHa et al., 2009). Em Minas Gerais, isso também se confirmou (Bello et al., 2007), embora o número de equídeos reagentes tenha sido sempre baixo no estudo.

Comparando-se os resultados dos três levantamentos realizados no Paraná, não fica claro se existem discrepâncias regionais no Estado. O presente estudo é o primeiro realizado com número elevado de animais examinados e com a preocupação de avaliar a situação com maior abrangência geográfica, pois os dois anteriores se restringiram à Região Metropolitana de Curitiba. Apesar de contemplar somente três das dez mesorregiôes geográficas do Estado (Fig. 1), os resultados devem ser considerados relevantes, porque essas localidades concentram quase um terço de toda a populaçáo de equinos existente. $\mathrm{O}$ número reduzido de equinos sororreagentes é o fato em comum nos três estudos. Na regiáo de Curitiba, animais utilizados para traçáo urbana não foram sororreagentes (LARA et al., 2006), enquanto dois equinos atletas da raça PSI

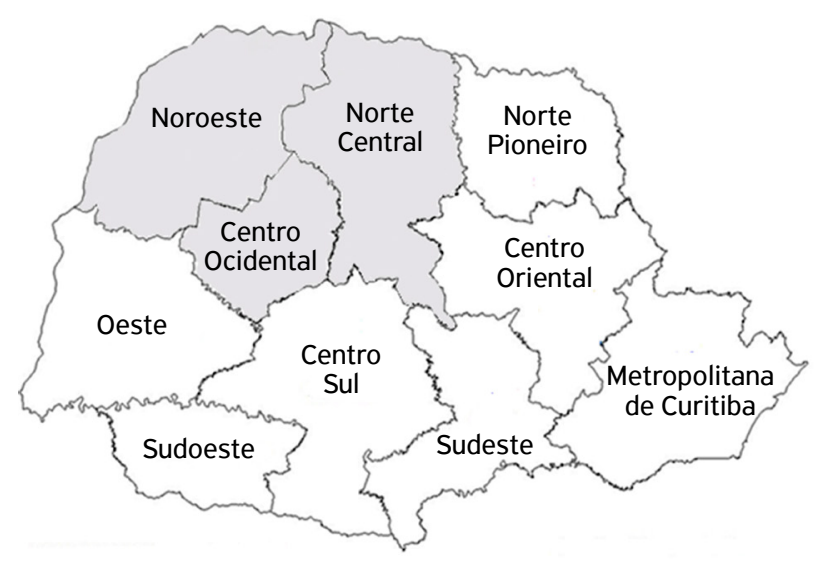

Figura 1. Mesorregiões geográficas do estado do Paraná, com destaque para as áreas de abrangência do estudo. 
apresentaram anticorpos contra o EVAV (LARA et al., 2003a). $\mathrm{O}$ conjunto dos resultados indica que a circulação do EVAV é baixa no estado do Paraná.

Pode-se concluir que, apesar da comprovaçáo de que o EVAV esteja em circulação na mesorregião Norte Central, a infecçáo ainda náo representa um problema de importância epidemiológica para os equinos paranaenses criados nas mesorregióes estudadas. Outros levantamentos devem ser realizados nas demais mesorregiôes paranaenses para que se conheça a situação no Estado por completo.

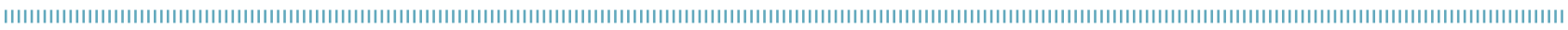
REFERÊNCIAS

AGUIAR, D.M.; CAVALCANTE, G.T.; LARA, M.C.C.S.H.; VILLALOBOS, E.M.C.; CUNHA, E.M.S.; OKUDA, L.H.; DE STÉFANO, E.; NASSAR, A.F.C.; SOUZA, G.O.; VASCONCELLOS, S.A.; LABRUNA, M.B.; CAMARGO, L.M.A; GENNARI, S.M. Prevalência de anticorpos contra agentes virais e bacterianos em equídeos do município de Monte Negro, Rondônia, Amazônia Ocidental Brasileira. Brazilian Journal of Veterinary Research and Animal Science, v.45, n.4, p.269-276, 2008.

BELL, A.S.; UDENI, D.V.M.; BALASURIYA, B.R.; MACLACHLAN, N.J. Equine viral arteritis. Clinical Techniques in Equine Practice, v.5, n.3, p.233-238, 2006.

BELLO, A.C.P.P.; CUNHA, A.P.; BRAZ, G.F.; LARA, M.C.C.S.H.; REIS, J.K.P.; HADDAD, J.P.H.; ROCHA, M.A.; LEITE, R.C. Frequency of equine viral arteritis in Minas Gerais State, Brazil. Arquivo Brasileiro de Medicina Veterinária e Zootecnia, v.59, n.4, p.1077-1079, 2007.

BRAGA, P.R.C.; LARA, M.C.C.S.H.; DIAS, A.; CUNHA, E.M.S.; VILLALOBOS, E.M.C.; RIBEIRO, M.G.; BORGES, A.S. Soroprevalência da arterite viral equina em mesorregiões paulistas entre $2007 \mathrm{e}$ 2008. Semina: Ciências Agrárias, v.33, n.4, p.1501-1506, 2012.

BRASIL. Produção Pecuária Municipal 2010. Instituto Brasileiro de Geografia e Estatística (IBGE), Brasília. 2010. Disponível em: <http://www.ibge.gov.br/home/estatistica/economia/ppm/2010/ ppm2010.pdf>. Acesso em: 08 out. 2011.

CUNHA, E.M.S.; VILLALOBOS, E.M.C.; NASSAR, A.F.C.; LARA, M.C.C.S.H.; PERES, N.F.; PALAZZO, J.P.C.; SILVA, A.; DE STEFANO, E.; PINO, F.A. Prevalência de anticorpos contra agentes virais em eqüídeos no sul do Estado de São Paulo. Arquivos do Instituto Biológico, v.76, n.2, p.165-171, 2009.

DIEL, D.G.; ALMEIDA, S.R.; WEIBLEN, R.; FRANDOLOSO, R.; ANZILIERO, D.; KREUTZ, L.C.; GROFF, F.H.S.; FLORES, E.F. Prevalência de anticorpos contra o vírus da influenza, da arterite viral e herpesvírus em eqüinos do Estado do Rio Grande do Sul, Brasil. Ciência Rural, v.36, n.5, p.1467-1473, 2006.

ECHEVERRIA, M.G.; PECORARO, M.R.; GALOSI, C.M.; ETCHEVERRIGARAY, M.E.; NOSSETO, E.O. The first isolation of equine arteritis in Argentina. Revue Scientifique et Technique Office International des Épizooties, v.22, n.3, p.1029-1033, 2003.

FERNANDES, W.R.; SOUZA, M.C.C. Determinação sorológica da Arterite Viral Equina em equinos hígidos, com abortamento e com sintomas de alteração do sistema respiratório. Revista Brasileira de Ciências Veterinárias, v.6, n.3, p.147-150, 1999.

HEINEMANN, M.B.; CORTEZ, A.; SOUZA, M.C.C.; GOTTI, T.; FERREIRA, F.; HOMEM, V.S.F.; FERREIRA NETO, J.S.; SOARES,
R.M.; SAKAMOTO, S.M.; CUNHA, E.M.S.; RICHTZENHAIN, L.J. Soroprevalência da anemia infecciosa equina, da arterite viral dos eqüinos e do aborto viral eqüino no município de Uruará, PA, Brasil. Brazilian Journal of Veterinary Research and Animal Science, v.39, n.1, p.50-53, 2002.

HOLYOAK, G.R.; BALASURIYA, U.B.R.; BROADDUS, C.C.; TIMONEY, P.J. Equine viral arteritis: current status and prevention. Theriogenology, v.70, n.3, p.403-414, 2008.

LARA, M.C.C.S.H.; BARROS FILHO, I.R.; VIANA, F.; GREGORY, L.; CUNHA, E.M.S.; CASTRO, A.F.; BIRGEL, E.H.; FERNANDES, W.R. Pesquisa de anticorpos contra o vírus da arterite dos eqüinos (VAE) e herpes eqüino tipo 1 (HVE-1), em cavalos criados em Curitiba, PR. A Hora Veterinária, v.23, n.135, p.51-53, $2003 a$.

LARA, M.C.C.S.H.; CUNHA, E.M.S.; FERRARI, C.I.L.; GREGORY, L.; CASTRO, A.F.; SILVA, L.H.Q.; FERNANDES, W.R.; BIRGEL, E.H. Ocorrência de anticorpos contra o vírus da arterite dos equinos em cavalos criados na região de Araçatuba, SP. Veterinária Notícias, v.9, n.2, p.69-73, 2003b.

LARA, M.C.C.S.H.; FERNANDES, W.R.; TIMONEY, P.J.; BIRGEL, E.H. Prevalência de anticorpos antivírus da arterite dos equinos em cavalos criados no Estado de São Paulo. Arquivo Brasileiro de Medicina Veterinária e Zootecnia, v.54, n.3, p.223-227, 2002.

LARA, M.C.C.S.H.; FURMAN, K.E.; BARROS FILHO, I.R.; VILLALOBOS, E.M.C.; CUNHA, E.M.S.; DECONTO, I.; BONACIM, J.; UTIME, R.A.; BIONDO, A.W. Detection of antibodies against equine viral arteritis virus (EVAV) and equine herpesvirus type 1 (EHV-1) in cart horses from Curitiba and surroundings, southern Brazil. Archives of Veterinary Science, v.1 1, n.3, p.11-14, 2006.

LIMA, M.; OSORIO, F.A. Arteriviridae. In: FLORES, E.F. (Ed.). Virologia Veterinária. 2. ed. Santa Maria: Editora da UFSM, 2012. p.741-758.

SENNE, D.A.; PEARSON, J.E.; CARBEY, E.A. Equine viral arteritis: a standard procedure for the virus neutralization test and comparison of results of a proficiency test performed at five laboratories. Proceedings of the United States Animal Health Association, v.89, p.29-34, 1985.

SOUZA, M.C.C.; SOUZA, M.C.A.M.; CUNHA, E.M.S.; GREGORY, L. Pesquisa de anticorpos contra o vírus da arterite dos equinos em cavalos criados no Vale do Paraíba, SP. Arquivos do Instituto Biológico, v.66, supl.1, p.40, 1999.

TIMONEY, P.J.; MCCOLLUM, W.H. Equine viral arteritis in perspective in relation to international trade. Journal of Equine Veterinary Science, v.13, n.1, p.50-52, 1993. 